\title{
ESTUDO SOBRE A APLICABILIDADE DA TEORIA CRADLE TO CRADLE C2C PARA A EMPRESA TÊXTIL CATARINENSE
}

Renata Vavolizza, Mestra (UFPR);
Liliane Iten Chaves, Doutora (UFPR)

A pesquisa apresenta possibilidades de inserção de práticas sustentáveis no processo produtivo têxtil, a partir de uma abordagem sistêmica e sustentável em design. Investigou-se a possibilidade de propor o principal conceito da teoria Cradle to Cradle - a Ecoefetividade - no contexto das indústrias têxteis ou de confecção em Santa Catarina. A pesquisa iniciou com uma Revisão Bibliográfica Sistemática (RBS), posteriormente foi realizada uma Revisão Bibliográfica Exploratória.

O levantamento de literaturas existentes construiu a fundamentação teórica, com ênfase na teoria Cradle to Cradle do designer William McDonough e do químico Michael Braungart. Devido a indústria têxtil possuir especificidades e uma cadeia produtiva complexa, a pesquisa configurou- se como um Estudo de Caso.

Para o Estudo de Caso, fez-se necessário delimitar a pesquisa, local, evento e processos a serem observados. Escolher as fontes de investigação das quais pretendia-se extrair a coleta de dados. A mesma deu-se com entrevistas semiestruturadas de resposta aberta, aplicadas a seis participantes de uma indústria de médio porte do norte catarinense e com a utilização da observação direta, sendo aplicado a observação espontânea e a observação sistemática, elaborada conjuntamente com a entrevista do protocolo de pesquisa, construído através de dois conceitos explicados por Braumgart e Mcdonought (2004):

- O conceito de Ecoeficiência: representa uma abordagem de sustentabilidade advinda da gestão, bastante estudada nas linhas tradicionais de pesquisa da área.

- O conceito de Ecoefetividade: representa uma abordagem de sustentabilidade advinda do design, onde o papel projetual está presente em sua perspectiva.

Pretendia-se descobrir se a Ecoeficiência e a Ecoefetividade estão presentes na realidade desta indústria têxtil; em que nível estão presentes; e em quais pontos a Ecoefetividade, representada pela teoria Cradle to Cradle teria possibilidades de inserção.

A estratégia de análise desta pesquisa é a triangulação das diferentes informações coletadas: triangulação das entrevistas entre três participantes do grupo de projeto, triangulação das entrevistas entre os participantes do grupo de gestão; e triangulação entre o resultado das entrevistas de ambos os grupos com a observação direta.

Registrou-se aproximadamente 250 páginas de transcrição e 500 fotografias documentais. Embora a pesquisa seja aprofundada em um caso, traz informações de difícil acesso a pessoas que trabalham ou pesquisam design para a sustentabilidade no setor têxtil e de confecção. Permite o entendimento do estado atual do Setor, na região norte de Santa Catarina.

O conjunto do documento promoveu subsídios para a Dissertação de Mestrado, comprometida em contribuir com a sociedade acadêmica e industrial, e com a disseminação de informações sobre práticas de sustentabilidade aplicáveis no setor têxtil e de confecção, que permitam embasamento específico para a construção de novos projetos envolvendo o design para a sustentabilidade.

\section{REFERÊNCIAS}

BAUMGARTNER, R. J. Critical perspectives of sustainable development research and practice. Journal of Cleaner Production, Elsevier, v. 19, ed. 8, p. 783-904, 2011.

MCDONOUGH, William; BRAUNGART, Michael. Cradle to cradle: remaking the way we make things. 2004.

MCDONOUGH, William; BRAUNGART, Michael. Cradle to cradle: criar e recriar ilimitadamente. São Paulo: G. Gili, 2013. 